\title{
Attitudes and Engagement of Pregnant and Postnatal Women With a Web-Based Emotional Health Tool (Mummatters): Cross-sectional Study
}

\author{
Nicole Reilly ${ }^{1,2^{*}}$, BPsyc, PhD; Marie-Paule Austin ${ }^{2,3^{*}}$, MBBS, MD \\ ${ }^{1}$ Centre for Health Service Development, Australian Health Services Research Institute, University of Wollongong, Wollongong, Australia \\ ${ }^{2}$ Perinatal \& Women's Mental Health Unit, St John of God Burwood Hospital \& School of Psychiatry, University of New South Wales, Burwood, \\ Australia \\ ${ }^{3}$ Royal Hospital for Women, Randwick, Australia \\ *all authors contributed equally
}

Corresponding Author:

Nicole Reilly, BPsyc, PhD

Centre for Health Service Development

Australian Health Services Research Institute

University of Wollongong

Building 234 (iC Enterprise 1), Innovation Campus

Wollongong, 2522

Australia

Phone: 610242218045

Email: nreilly@uow.edu.au

\section{Abstract}

Background: Mummatters is a web-based health tool that allows women to self-assess the symptoms of depression and the presence of psychosocial risk factors throughout pregnancy and the postnatal period. It aims to increase women's awareness of their own symptoms or risk factors and their knowledge of the available support options, to encourage engagement with these support options (as appropriate), and to facilitate communication about emotional health issues between women and their health care providers.

Objective: The aim of this study is to report the uptake of mummatters; the sociodemographic and psychosocial risk profiles of a subsample of users; and the acceptability, credibility, perceived effect, and motivational appeal of the tool. The help-seeking behaviors of the subsample of users and barriers to help seeking were also examined.

Methods: Mummatters was launched in November 2016. Women who completed the mummatters baseline assessment were invited to complete a web-based follow-up survey 1 month later.

Results: A total of 2817 women downloaded and used mummatters between November 13, 2016, and May 22, 2018 , and 140 women participated in the follow-up study. Approximately half of these women $(51 \% ; 72 / 140)$ were Whooley positive (possible depression), and 43\% (60/140) had an elevated psychosocial risk score on the Antenatal Risk Questionnaire. Mummatters was rated favorably by pregnant and postnatal women in terms of its acceptability (94\%-99\%), credibility (93\%-97\%), appeal (78\%-91\%), and potential to affect a range of health behaviors specific to supporting emotional wellness during the perinatal period (78\%-93\%). Whooley-positive women were more likely to speak with their families than with a health care provider about their emotional health. Normalizing symptoms and stigma were key barriers to seeking help.

Conclusions: Although mummatters was rated positively by consumers, only 53\% (19/36) to 61\% (22/36) of women with possible depression reported speaking to their health care providers about their emotional health. There was a trend for more prominent barriers to seeking help among postnatal women than among pregnant women. Future studies that investigate whether social barriers to seeking help are greater once a woman has an infant are warranted. Such barriers potentially place these women at greater risk of remaining untreated, as the demands on them are greater.

(J Med Internet Res 2021;23(3):e18517) doi: 10.2196/18517 


\section{KEYWORDS}

pregnancy; postpartum; self-assessment; depression; risk

\section{Introduction}

\section{Background}

Overall, 1 in 7 women experience some form of mental health morbidity during pregnancy and the first postnatal year (the perinatal period) [1,2]. When left untreated, perinatal depression and anxiety may persist for years after birth and can affect not only the woman's capacity to parent but also the emotional well-being of the infant and other family members [3,4]. The importance of early detection and intervention in this susceptible population has been widely acknowledged [5-9].

The health service systems in place for routine maternity care in Australia have provided a unique opportunity to introduce perinatal mental health promotion, prevention, and early intervention programs. These programs and related clinical guidelines aim for the early identification of possible or probable illness, or risk of illness, and then to monitor or intervene as appropriate, with a view to improve maternal mental health outcomes $[6,10]$. However, there are disparities in access to these programs, with women who give birth in the private maternity sector, for example, being less likely to be assessed across various domains of psychosocial health during pregnancy or the postpartum period [11-13].

In response to this inequity of access, Bupa Australia collaborated with perinatal mental health and consumer teams to develop a web-based tool, mummatters [14], which allows women to self-assess for the symptoms of depression and the presence of psychosocial risk factors throughout the perinatal period. mummatters aims to increase women's awareness of their own symptoms or risk factors and their knowledge of the available support options, encourage engagement with these support options (as appropriate), and facilitate communication about emotional health issues between women and their health care providers.

\section{Objective}

The aim of this study was to report on the uptake of mummatters; the sociodemographic and psychosocial risk profiles of a subsample of users; and the acceptability, credibility, perceived effect, and motivational appeal of the tool to pregnant and postnatal women. The help-seeking behaviors of women who used mummatters and barriers to help seeking were also examined.

\section{Methods}

\section{Mummatters Overview}

Mummatters is a web-based tool that is available free of charge via the Bupa website [14]. Its web-based design allows access from a range of computing and mobile devices. Users can bookmark the website or save mummatters to the home page of their devices, where it appears as an icon. Internet access is required to use the features of the tool.
After downloading mummatters, women are invited to answer a small number of demographic questions (including current gestation or infant age and maternity care sector), followed by a baseline assessment comprising the Whooley questions [15,16] and the Antenatal Risk Questionnaire (ANRQ; and its postnatal equivalent) [17].

The Whooley depression case-finding questions are recommended for use in the perinatal period by the National Institute for Health and Care Excellence [8]. The 2-item questionnaire has been shown to have a high sensitivity $(0.95$; 95\% CI $0.88-0.97)$ and modest specificity $(0.65 ; 95 \%$ CI 0.56-0.74) [18]. The Whooley questions are as follows: (1) "During the past month, have you often been bothered by feeling down, depressed or hopeless?" and (2) "During the past month, have you often been bothered by having little interest or pleasure in doing things?" [15]. These depression-related questions are followed by a third question that is asked to women who responded "yes" to either of the 2 above-mentioned questions ("Is this something you feel you need or want help with?") [16]. Women were considered to be Whooley positive (possible depressive episode) if they answered "yes" to either/both questions 1 or 2 [8].

The ANRQ is a validated self-report measure that was developed by a panel of experts, based on evidence relating to salient risk factors associated with perinatal mental health disorders, particularly depression and anxiety, and on the face and construct validity of these factors. Its capacity to identify women at increased risk for these conditions has been demonstrated [17]. Although initially developed for the antenatal period, the ANRQ has been used during the postnatal period for research and clinical practice $[19,20]$. Australia's current clinical practice guidelines for mental health care in the perinatal period recommend the use of the ANRQ for the assessment of psychosocial risk [6].

A key feature of mummatters is its computer-based decision aid that combines responses to the Whooley questions and ANRQ to generate tailored follow-up messages and provide help-seeking information, as appropriate. For example, women who are Whooley positive automatically receive a message encouraging them to make an appointment to discuss their emotional health with a trusted health care professional. The tool also allows women to give permission for a letter addressed to their health care provider to be generated, which includes a summary of their results as well as full copies of their completed measures. Women are also given ready access to additional information and links to resources that aim to support them in actively looking after their emotional well-being. After the completion of the initial baseline assessment, mummatters sends monthly prompts for women (irrespective of their baseline scores) to complete follow-up assessments to monitor their emotional health and well-being. Women can also create an individualized wellness action plan and can opt to receive inspirational messages sent monthly via SMS or email. 


\section{Data Collection and Research Participants}

There were 2 primary sources of data for this evaluation. The first was mummatters use data that women consented to being used for research purposes via a within-tool agreement. These use data included a unique identification number as well as deidentified demographic and clinical information provided during the initial pregnancy or postnatal assessment.

The second data source was a research-specific data set that required additional consent. All women who used mummatters at least once during pregnancy or postnatally and who indicated their willingness to be contacted about the study were emailed and invited to participate. To be eligible, women were also required to be currently living in Australia, have access to the internet, and be able to complete the measures in English. Eligible women who agreed to participate gave informed consent and completed the additional study measures via the web-based Key Survey (TM) platform. A reminder email was sent by the research team to women who did not complete the study measures within 1 week, with 2 further reminders sent at weekly intervals thereafter (up to a maximum of 3 reminders).

Participants completed questions relating to the acceptability, credibility, likeability, perceived effect, and motivational appeal of the tool. Participants were also asked about help-seeking behaviors in the previous month and barriers to help seeking. Where possible, these questions were replicated or modified from previous studies for methodological consistency [21,22]. These data were linked to the use data of the participants via their unique identification numbers.

\section{Ethical Approval}

The study was approved by the Human Research Ethics Committee (HREC) of St John of God Health Care (HREC reference number: 735$)$.

\section{Results}

Sociodemographic and Psychosocial Profile of Mummatters Evaluation Participants

A total of 2817 women downloaded and completed the mummatters baseline measures between November 13, 2016, and May 22, 2018. Of these, 26.80\% (755/2817) indicated their willingness to be contacted about the study and were emailed an information sheet, consent form, and link to the study measures approximately 4 weeks after indicating their expression of interest. Of these, 33.8\% (255/755) women agreed to participate in the study; among these, 91 women dropped out of the survey immediately after indicating their consent (ie, before completing any of the research questions). Of the remaining 164 women, 140 had sufficient research data and were subsequently included in the analyses (ie, 5\% (140/2817) of all mummatters users and $18.5 \%$ (140/755) of all women emailed about the research). The demographic profiles of the 140 women who participated are presented in Table 1.

There were no significant differences between pregnant or postnatal mummatters users who were and were not included in the study in terms of Whooley-positive status (antenatal: $\chi^{2}(2)=1.0 ; P=.60$ and postnatal: $\left.\chi^{2}(2)=2.5 ; P=.29\right)$, ANRQ total score (antenatal: $t_{1331}=-1.32 ; P=.19$ and postnatal: $t_{1369}=-0.05$; $P=.96$ ), private maternity sector (antenatal: $\chi^{2}(2)=1.1 ; P=.78$ and postnatal: $\left.\chi^{2}(1)=0.7 ; P=.68\right)$, gestation $\left(t_{1377}=0.34 ; P=.73\right)$, or infant age $\left(t_{1433}=1.38 ; P=.17\right)$ at baseline assessment.

The results of the mummatters baseline psychosocial assessment (Whooley questions and psychosocial risk questionnaire) for participants are summarized in Table 2. During pregnancy, $49 \%$ $(n=36 / 73)$ of participants were Whooley positive; one or both of the Whooley questions were endorsed by $15 \%(11 / 73)$ and $34 \%(25 / 73)$ of participating women, respectively. In the postnatal period, 36 of 67 (54\%) participants were Whooley positive, with $31 \%$ (21/67) of women endorsing one question and $22 \%(15 / 67)$ endorsing both questions. Across the perinatal period, women who endorsed both Whooley questions were significantly more likely to answer "yes" to the third Whooley help question than women who endorsed one question only (antenatal: $\chi^{2}(1)=5.7 ; P=.02$ and postnatal: $\chi^{2}(1)=5.2 ; P=.02$ ). 
Table 1. Sociodemographic characteristics of mummatters evaluation participants.

\begin{tabular}{|c|c|c|}
\hline Characteristic & Antenatal period (baseline; $\mathrm{n}=73$ ) & Postnatal period (baseline; $\mathrm{n}=67$ ) \\
\hline \multicolumn{3}{|c|}{ Gestation or infant age at first mummatters baseline assessment (weeks) } \\
\hline Mean (SD) & $20.96(11.19)$ & $15.28(24.11)$ \\
\hline Range & $4-40$ & $1-178$ \\
\hline \multicolumn{3}{|l|}{ Maternal age (years) } \\
\hline Mean (SD) & $32.97(4.60)$ & $32.70(4.20)$ \\
\hline Range & $24-43$ & $25-45$ \\
\hline Partnered $^{\mathrm{a}}, \mathrm{n}(\%)$ & $68(96)$ & $65(99)$ \\
\hline First child $^{\mathrm{b}}, \mathrm{n}(\%)$ & $42(62)$ & $28(44)$ \\
\hline Australian born ${ }^{\mathrm{b}}, \mathrm{n}(\%)$ & $60(88)$ & $49(78)$ \\
\hline \multicolumn{3}{|l|}{ Maternity sector ${ }^{\mathbf{c}}, \mathbf{n}(\%)$} \\
\hline Public & $32(44)$ & $30(46)$ \\
\hline Private & $37(51)$ & $36(55)$ \\
\hline Undecided & $4(6)$ & $N / A^{d}$ \\
\hline \multicolumn{3}{|l|}{ Residential area $^{\mathrm{a}}, \mathrm{n}(\%)$} \\
\hline Metropolitan & $51(72)$ & $43(65)$ \\
\hline Regional & $14(20)$ & $20(30)$ \\
\hline Rural & $6(9)$ & $3(5)$ \\
\hline \multicolumn{3}{|c|}{ Highest educational level $^{\mathbf{a}}, \mathbf{n}(\%)$} \\
\hline Highschool & $6(9)$ & $4(6)$ \\
\hline $\mathrm{TAFE}^{\mathrm{e}}$ or diploma & $20(28)$ & $15(23)$ \\
\hline Bachelor's degree & $30(42)$ & $28(42)$ \\
\hline Postgraduate degree & $15(21)$ & $19(29)$ \\
\hline \multicolumn{3}{|c|}{ Current employment status ${ }^{\mathrm{a}}, \mathrm{n}(\%)$} \\
\hline On maternity leave & $19(27)$ & $45(68)$ \\
\hline Full time & $33(47)$ & $4(6)$ \\
\hline Part time & $12(17)$ & $6(9)$ \\
\hline Unemployed & $7(10)$ & $11(17)$ \\
\hline \multicolumn{3}{|c|}{ Income management $t^{a, f}, \mathbf{n}(\%)$} \\
\hline Difficult & $17(24)$ & $26(39)$ \\
\hline Not difficult & $54(76)$ & $40(61)$ \\
\hline
\end{tabular}

${ }^{\mathrm{a}}$ Excludes 2 antenatal women and 1 postnatal woman with missing data.

${ }^{\mathrm{b}}$ Excludes 5 antenatal women and 4 postnatal women with missing data.

${ }^{\mathrm{c}}$ Excludes 1 postnatal woman with missing data.

${ }^{\mathrm{d}} \mathrm{N} / \mathrm{A}$ : not applicable.

${ }^{\mathrm{e}}$ TAFE: Technical and Further Education.

${ }^{\mathrm{f}}$ Responses to the question "How do you manage on the income you have available" were divided into difficult ("It is impossible," "It is difficult all of the time," and "It is difficult some of the time") or not difficult ("It is too bad" and "It is easy") responses.

Columns may not total $100 \%$ due to rounding. 
Table 2. Psychosocial profile of mummatters evaluation participants.

\begin{tabular}{|c|c|c|}
\hline Characteristic & Antenatal period (baseline; $\mathrm{n}=73$ ) & Postnatal period (baseline; $n=67$ ) \\
\hline \multicolumn{3}{|l|}{ Psychosocial risk questionnaire $\left(\mathrm{ANRQ}^{\mathbf{a}}\right)$ total score } \\
\hline Mean (SD) & 23.11(10.64) & $23.09(10.00)$ \\
\hline Range & $6-53$ & $7-49$ \\
\hline Whooley positive $^{\mathrm{b}}, \mathrm{n}(\%)$ & $36(49)$ & $36(54)$ \\
\hline ANRQ score $\geq 23, \mathrm{n}(\%)$ & $30(41)$ & $30(45)$ \\
\hline \multicolumn{3}{|l|}{ ANRQ item, n (\%) } \\
\hline High trait anxiety (being a worrier) ${ }^{\mathrm{c}}$ & $20(27)$ & $22(33)$ \\
\hline Perfectionistic traits ${ }^{c}$ & $19(26)$ & $14(21)$ \\
\hline Past sexual or physical abuse & $17(23)$ & $9(13)$ \\
\hline Significant past mental health issues ${ }^{\mathrm{d}}$ & $31(22)$ & $18(27)$ \\
\hline Major stressors in the last 12 months $\mathrm{e}^{\mathrm{e}}$ & $16(22)$ & $18(27)$ \\
\hline Emotional abuse in childhood & $14(19)$ & $11(16)$ \\
\hline Growing up with emotionally unsupportive mother ${ }^{\mathrm{c}}$ & $13(18)$ & $18(27)$ \\
\hline Lack of support with the baby ${ }^{\mathrm{c}}$ & $7(10)$ & $12(18)$ \\
\hline Emotionally unsupportive partner ${ }^{\mathrm{c}}$ (or no partner) & $6(8)$ & $4(6)$ \\
\hline
\end{tabular}

${ }^{a}$ ANRQ: Antenatal Risk Questionnaire.

${ }^{\mathrm{b}}$ Endorsed one or both of the two Whooley questions.

${ }^{\mathrm{c} A n t e n a t a l ~ R i s k ~ Q u e s t i o n n a i r e ; ~ s c a l e d ~ i t e m s ~ w e r e ~ d i c h o t o m i z e d ~ i n t o ~ l o w ~ s c o r i n g ~(1-3) ~ o r ~ h i g h ~ s c o r i n g ~(4 ~ o r ~ m o r e), ~ c o n s i s t e n t ~ w i t h ~ t h e ~ m e t h o d o l o g y ~}$ used in previous research [23,24].

${ }^{\mathrm{d}}$ Item considered endorsed if participants responded "yes" to depression or other past mental health problems for which professional help was sought or which significantly interfered with work and relationships (score of 4 or more).

e Item considered endorsed if participants responded "yes" to experiencing a major stressor in the previous 12 months which caused a significant degree of distress (score of 4 or more).

Overall, 33\% (24/73) of women who completed the antenatal baseline assessment did not endorse any significant risk factors on the ANRQ, 26\% (19/73) endorsed 1 significant risk factor, $15 \%$ (11/73) endorsed 2 significant risk factors, and 26\% (19/73) had 3 or more significant risk factors. Postnatally, $19 \%$ (13/67), $24 \%(16 / 67), 31 \%(21 / 67)$, and 25\% (17/67) of women endorsed none, 1,2 , and 3 or more risk factors on the ANRQ, respectively. A total of $41 \%$ (30/73) of antenatal participants and $45 \%(30 / 67)$ postnatal participants scored 23 or more, which is the cutoff score for the ANRQ. Women who score above the cutoff are considered to be experiencing a significant accumulation of risk factors that are associated with an increased risk of developing a clinical depression or anxiety disorder [17].

\section{Participant Experience and Feedback}

The mean time taken by women to complete the mummatters baseline questions was 4 minutes (antenatal women: mean 4.16 minutes, SD 11.27 minutes; postnatal women: mean 3.88 minutes, SD 8.48 minutes). Most pregnant and postpartum women rated mummatters favorably on a range of feedback parameters (Table 3). Of note, most pregnant and postnatal users regarded mummatters as acceptable (94.0\%-98.6\%), credible (93.2\%-97.3\%), appealing (78.1\%-91.0\%), and potentially helpful in affecting a range of health behaviors specific to supporting emotional wellness during the perinatal period (78.1\%-92.5\%). 
Table 3. Participant agreement with feedback statements relating to the use of mummatters.

\begin{tabular}{|c|c|c|}
\hline Feedback statement & Antenatal period $(\mathrm{n}=73), \mathrm{n}(\%)^{\mathrm{a}}$ & Postnatal period $(\mathrm{n}=67), \mathrm{n}(\%)^{\mathrm{a}}$ \\
\hline \multicolumn{3}{|l|}{ Acceptability } \\
\hline $\begin{array}{l}\text { I felt comfortable completing questions about my emotional health and } \\
\text { well-being using mummatters }\end{array}$ & $72(99)$ & $63(94)$ \\
\hline \multicolumn{3}{|l|}{ Credibility } \\
\hline The information I got from mummatters can be trusted & $71(97)$ & $64(96)$ \\
\hline The information I got from mummatters was useful & $68(93)$ & $64(96)$ \\
\hline \multicolumn{3}{|l|}{ Perceived effect } \\
\hline $\begin{array}{l}\text { The information in mummatters helped me better understand the importance } \\
\text { of having good emotional health in the transition to motherhood }\end{array}$ & $65(89)$ & $62(93)$ \\
\hline mummatters helped me learn about the symptoms of depression & $57(78)$ & $61(91)$ \\
\hline $\begin{array}{l}\text { mummatters helped me learn about some common risk factors for depression } \\
\text { and anxiety during pregnancy and in the year after birth }\end{array}$ & $63(86)$ & $61(91)$ \\
\hline $\begin{array}{l}\text { mummatters will help me pay closer attention to my emotional health and } \\
\text { well-being }\end{array}$ & $58(80)$ & $54(81)$ \\
\hline $\begin{array}{l}\text { mummatters would help me feel more comfortable in seeking support for } \\
\text { emotional health issues during pregnancy and in the year after birth, if I } \\
\text { needed it }\end{array}$ & $62(85)$ & $55(83)$ \\
\hline $\begin{array}{l}\text { mummatters would help reduce the stigma of seeking help for emotional } \\
\text { health issues during pregnancy and in the year after birth, if I needed it }\end{array}$ & $65(89)$ & $56(84)$ \\
\hline $\begin{array}{l}\text { mummatters increased my awareness of additional resources for emotional } \\
\text { well-being during pregnancy and in the year after birth }\end{array}$ & $63(86)$ & $59(88)$ \\
\hline $\begin{array}{l}\text { mummatters provides practical solutions to managing emotional health issues } \\
\text { during pregnancy and in the year after birth }\end{array}$ & $60(82)$ & $60(90)$ \\
\hline $\begin{array}{l}\text { The report that I can download in mummatters would help me talk to my } \\
\text { health care provider about my emotional well-being, if I needed to }\end{array}$ & $63(86)$ & $58(87)$ \\
\hline $\begin{array}{l}\text { The information provided in mummatters could help me manage my emo- } \\
\text { tional well-being in the future }\end{array}$ & $63(86)$ & $61(91)$ \\
\hline \multicolumn{3}{|l|}{ Motivational appeal } \\
\hline I would use mummatters again & $66(90)$ & $61(91)$ \\
\hline I would tell friends to use mummatters & $57(78)$ & $57(85)$ \\
\hline \multicolumn{3}{|l|}{ Likeability } \\
\hline It was easy to find the information I wanted in mummatters & $66(90)$ & $59(88)$ \\
\hline The information I got from mummatters was relevant to me & $66(90)$ & $62(93)$ \\
\hline Overall, the features of mummatters met my expectations & $58(80)$ & $54(81)$ \\
\hline
\end{tabular}

${ }^{\mathrm{a}}$ Numbers and percentages indicate those who agreed or strongly agreed with each statement.

Help-Seeking Behaviors and Barriers to Help Seeking

The help-seeking behaviors of Whooley-positive women (ie, women endorsing one or both of the Whooley depression questions) in the month before completing the study survey as well as the barriers to help seeking are presented in Table 4 . Overall, these women were the most likely to discuss their emotional health with their partners or family during both pregnancy $(33 / 36,92 \%)$ and the postnatal period $(30 / 36,83 \%)$.
Other common sources of support were friends (56\%-61\%), health care providers (53\%-61\%), and books or print materials (56\%-64\%). Women were more likely to report using complementary therapies for their emotional health during pregnancy than after birth. Interestingly, only 23\% (5/22) of Whooley-positive women who spoke with a health care provider during pregnancy took their mummatters report to the appointment with them, which decreased to $11 \%(2 / 19)$ in the postnatal period. 
Table 4. Help-seeking behaviors and barriers to help seeking in the month before completing the study survey among antenatal and postnatal Whooley-positive women.

\begin{tabular}{|c|c|c|c|}
\hline Help-seeking behaviors and barriers & Antenatal period $(\mathrm{n}=36), \mathrm{n}(\%)$ & Postnatal period $(\mathrm{n}=36), \mathrm{n}(\%)$ & $P$ value $^{\mathrm{a}}$ \\
\hline \multicolumn{4}{|c|}{ Help-seeking behaviors in the month before completing the study survey } \\
\hline Spoke to health care professional ${ }^{\mathrm{b}}$ & $22(61)$ & $19(53)$ & .47 \\
\hline Partner or family & $33(92)$ & $30(83)$ & .48 \\
\hline Friends & $22(61)$ & $20(56)$ & .54 \\
\hline Internet & $13(36)$ & $15(42)$ & .42 \\
\hline Books or print materials & $20(56)$ & $23(64)$ & .53 \\
\hline Lifestyle changes & $9(25)$ & $15(42)$ & .10 \\
\hline Complementary therapies (including supplements) & $16(44)$ & $7(19)$ & .04 \\
\hline Started or continued medication & $7(19)$ & $3(8)$ & .19 \\
\hline Phone helpline & $0(0)$ & $3(8)$ & .24 \\
\hline Day stay or residential parenting service & $\mathrm{N} / \mathrm{A}^{\mathrm{c}}$ & $3(8)$ & N/A \\
\hline Hospital emergency department or admission & $0(0)$ & $2(6)$ & .49 \\
\hline \multicolumn{4}{|c|}{ Barriers to help-seeking in the month before completing the study survey } \\
\hline Did not think needed help & $7(19)$ & $11(30)$ & .31 \\
\hline Normalizing symptoms & $11(31)$ & $17(46)$ & .18 \\
\hline Not aware of services & $6(17)$ & $6(16)$ & .96 \\
\hline Would feel like a failure & $6(17)$ & $12(32)$ & .12 \\
\hline Fear of judgment & $10(28)$ & $17(46)$ & .11 \\
\hline Worried about side effects of treatment & $6(17)$ & $4(11)$ & .52 \\
\hline Could not afford it & $6(17)$ & $3(8)$ & .31 \\
\hline Could not arrange childcare or transport & $0(0)$ & $4(11)$ & .12 \\
\hline
\end{tabular}

${ }^{\mathrm{a}}$ Chi-square test was used when $\mathrm{n}$ is $>5$, and Fisher exact test was used when $\mathrm{n}$ is $<5$.

${ }^{\mathrm{b}}$ Includes midwife, child health nurse, general practitioner, obstetrician, counselor, psychologist, and psychiatrist.

${ }^{\mathrm{c}} \mathrm{N} / \mathrm{A}$ : not applicable.

The most common barriers to seeking additional help or support reported by Whooley-positive women were personal or social in nature. For example, 46\% (17/36) of postnatal participants normalized their symptoms or feared that they would be negatively judged if they asked for help, and up to one-third of women reported that they would feel like a failure. The proportion of women reporting these effects of stigma was greater in the postnatal period than during pregnancy, although these differences were not statistically significant.

\section{Discussion}

\section{Principal Findings}

This study sought to report on the uptake of mummatters and to provide insights into the experience, psychosocial profile, and help-seeking behaviors of women who engaged with this free, web-based self-assessment tool. Approximately 3000 women downloaded mummatters in 18 months. The results demonstrated that the tool was positively appraised by both pregnant and postnatal users, with high levels of reported acceptability, credibility, likeability, perceived effect, and motivational appeal. Approximately half of the women who used mummatters had chosen private maternity care for their current pregnancy or birth $(48 \% ; 1358 / 2817)$, suggesting that the tool was reaching a population that was known to be less likely to be offered depression screening and psychosocial assessment as a routine component of their antenatal and postnatal care.

Existing Australian research has reported elevated ANRQ scores among $14 \%-32 \%$ of women [23-25] in the general perinatal population, and although there is no Australian comparison data available for the Whooley questions, previous community-based studies have reported Whooley-positive rates of between $10 \%$ and $51 \%$ [26,27]. In comparison, up to $45 \%$ of women in this study scored above the recommended clinical cutoff score on the ANRQ and up to $54 \%$ were Whooley positive, suggesting that women who are at greater risk of poorer emotional health or parenting outcomes or who are experiencing current symptoms of depression are using mummatters and finding it highly acceptable. In keeping with recent research, this pattern of results may also reflect that an anonymous web-based assessment makes it easier for women to give an honest account of how they are feeling [28,29]. Although depression screening and psychosocial assessment are largely acceptable to most 
women and health providers $[17,23,24,30]$, recent research has shown that women who are most likely to need mental health care during the perinatal period are also those least likely to be honest with their health care providers when responding to questions about their mental health [31].

It is well-established that fear and shame are significant factors in women's decisions to seek or accept help for mental health issues during the perinatal period [32]. Approximately half of the women normalized their symptoms and were particularly concerned with how others would judge them if they admitted that they were struggling emotionally with motherhood. The barriers presented by these stigmatizing beliefs remain despite general population community surveys showing a high rate of disagreement with negative stereotypes about depression and motherhood, including disagreeing with the view that women with postnatal depression are unable to be good mothers [33].

Up to $47 \%$ of Whooley-positive women in this study did not speak to a health care professional about how they were feeling in the month after completing the mummatters baseline assessment, and only a few $(10.5 \%-22.7 \%)$ of those that did took the downloadable mummatters report to their appointment. Although this is in line with previous Australian research that shows that up to $50 \%$ of women do not seek help for emotional health issues during the perinatal period despite being identified as in need of additional support [34,35], there is a clear need to understand why the report was being underutilized and how this can be made more useful, particularly given that women had already taken a first step in seeking a way to evaluate their symptoms. Seeking women's consent to automatically send the reports from mummatters to a nominated health care provider is one possible response so that the onus to seek care does not solely lie on the women, whose symptoms may inherently make it difficult to seek support. However, this option assumes that women will have continuity of care, but this is not always possible in contexts where care is delivered across hospital maternity care systems and postnatal community-based primary care systems and between the public and private health care sectors. Gathering women's views on how this feature can be improved or made more acceptable to users was beyond the scope of this study but is critical to inform future updates of the tool. Consistent with other Australian research [22,35,36], this study showed that family and friends are key support options for many women during pregnancy and the postnatal period. This again highlights the critical importance of targeting partners, family, and social networks in community awareness campaigns and early intervention programs for perinatal mental health. However, such campaigns must be complemented by support and treatment approaches that are well resourced, available, and enhance timely access to appropriate follow-up care. Interestingly, both pregnant and postnatal women in this study were more likely to report seeking support or information about their emotional health from books or print materials than the internet. This was despite women already being engaged with mummatters as a web-based tool and despite the increasing availability of locally developed internet-based resources and interventions [37]. The feasibility of partnering with service providers to directly link women to evidence-based web-based and telehealth treatment programs in future iterations of mummatters is currently being explored.

\section{Strengths and Limitations}

This study has several limitations. The sample size was small; however, based on the limited comparison data available, participants were representative of all mummatters users. Although it was a self-selected sample, a greater than expected proportion of participants endorsed possible depression or a substantial number of psychosocial risk factors, predisposing them to developing a mental health episode. Thus, we were able to examine the concerns of more susceptible women more closely in terms of help-seeking behaviors and barriers.

\section{Conclusions}

Previous research has reported on the engagement and real-world clinical utility of web-based approaches to self-administered screening for mental health conditions [38-41]; however, such approaches have not been adequately evaluated in perinatal populations. This study provided insight into the profile, experience, and help-seeking behaviors of women who used mummatters, a freely available web-based tool, and our results will help inform the review and further development of the tool. Although mummatters was rated positively by consumers, only $53 \%(19 / 36)$ to $61 \%(22 / 36)$ of women with possible depression reported speaking to their health care provider about this. This was more notable (though not statistically significant) among postnatal women than among pregnant women, suggesting that the barriers to help seeking are greater once a woman has an infant. Such barriers potentially place these women at greater risk of remaining untreated, as the demands on them are greater. This warrants further investigation in future studies.

Although consumer-driven risk assessments and symptom checklists are becoming more readily available for perinatal women, the need to keep training health care providers to engage women and ask the right questions to start the conversation around emotional well-being remains imperative [42]. Multiple but complementary approaches may be necessary given the well-documented findings, supported by our study, that many women do not seek formal assistance from their health care providers even when they are encouraged to do so. Future research should also focus on whether engagement with self-assessment tools of this type, including frequency and duration of engagement, is associated with longer-term improvements in mental health and health-related quality of life.

\section{Acknowledgments}

The authors thank the women who generously gave their time to participate in this study. The authors gratefully acknowledge the infrastructure funding of St John of God Health Care and thank the clinical leadership, health and care solutions, and research and partnerships divisions of Bupa Australia for their investment in mummatters and collaborative approach to research translation 
and knowledge exchange. NR also thanks Australian Rotary Health, the University of Newcastle (2018-2020), and the University of Wollongong (2020-2023) for postdoctoral fellowship funding support. The funding bodies had no involvement in the design of the study, analysis and interpretation of data, or writing of the manuscript.

\section{Conflicts of Interest}

None declared.

\section{References}

1. Gaynes BN, Gavin N, Meltzer-Brody S, Lohr KN, Swinson T, Gartlehner G, et al. Perinatal depression: prevalence, screening accuracy, and screening outcomes. Evid Rep Technol Assess (Summ) 2005 Feb(119):1-8. [Medline: 15760246]

2. Dennis C, Falah-Hassani K, Shiri R. Prevalence of antenatal and postnatal anxiety: systematic review and meta-analysis. Br J Psychiatry 2017 May;210(5):315-323. [doi: 10.1192/bjp.bp.116.187179] [Medline: 28302701]

3. Woolhouse H, Gartland D, Mensah F, Brown SJ. Maternal depression from early pregnancy to 4 years postpartum in a prospective pregnancy cohort study: implications for primary health care. BJOG 2015 Feb;122(3):312-321. [doi: 10.1111/1471-0528.12837] [Medline: 24844913]

4. Stein A, Pearson RM, Goodman SH, Rapa E, Rahman A, McCallum M, et al. Effects of perinatal mental disorders on the fetus and child. Lancet 2014 Nov 15;384(9956):1800-1819. [doi: 10.1016/S0140-6736(14)61277-0] [Medline: 25455250]

5. RANZCOG. Mental Health Care in the Perinatal Period (C-Obs 48). Melbourne: Royal Australian and New Zealand College of Obstetricians and Gynaecologists; 2018. URL: https://ranzcog.edu.au/statements-guidelines [accessed 2020-10-15]

6. Austin MP, Highet N. and the Expert Working Group. Mental Health Care in the Perinatal Period: Australian Clinical Practice Guideline. Melbourne: COPE: Centre of Perinatal Excellence; 2017. URL: https://cope.org.au/wp-content/uploads/ 2017/10/Final-COPE-Perinatal-Mental-Health-Guideline.pdf [accessed 2020-10-15]

7. DoH. Clinical Practice Guidelines: Pregnancy Care. Canberra: Department of Health, Australian Government; 2018. URL: https://www.health.gov.au/resources/pregnancy-care-guidelines [accessed 2020-10-15]

8. NICE. NICE Clinical Guideline 192. Antenatal and postnatal mental health: Clinical management and service guidance. London: National Institute for Health and Care Excellence; 2014. URL: https://www.nice.org.uk/guidance/cg192 [accessed 2020-10-15]

9. O'Connor E, Rossom RC, Henninger M, Groom HC, Burda BU. Primary Care Screening for and Treatment of Depression in Pregnant and Postpartum Women: Evidence Report and Systematic Review for the US Preventive Services Task Force. JAMA 2016 Jan 26;315(4):388-406. [doi: 10.1001/jama.2015.18948] [Medline: 26813212]

10. DoHA. National Perinatal Depression Initiative 2008 - 2013. Canberra: Department of Health and Ageing, Australian Government URL: http://www.health.gov.au/internet/main/publishing.nsf/Content/mental-perinat [accessed 2020-10-15]

11. Reilly N, Harris S, Loxton D, Chojenta C, Forder P, Milgrom J, et al. Disparities in reported psychosocial assessment across public and private maternity settings: a national survey of women in Australia. BMC Public Health 2013 Jul 04;13:632 [FREE Full text] [doi: 10.1186/1471-2458-13-632] [Medline: 23826627]

12. Yelland J, Brown SJ. Asking women about mental health and social adversity in pregnancy: results of an Australian population-based survey. Birth 2014 Mar;41(1):79-87. [doi: 10.1111/birt.12083] [Medline: 24571172]

13. San Martin Porter MA, Betts K, Kisely S, Pecoraro G, Alati R. Screening for perinatal depression and predictors of underscreening: findings of the Born in Queensland study. Med J Aust 2019 Jan;210(1):32-37. [doi: 10.5694/mja2.12030] [Medline: $\underline{30636310]}$

14. Bupa Australia. mummatters. Melbourne: Bupa Australia Health Pty Ltd; 2016. URL: https://www.bupa.com.au/mummatters [accessed 2020-10-15]

15. Whooley MA, Avins AL, Miranda J, Browner WS. Case-finding instruments for depression. Two questions are as good as many. J Gen Intern Med 1997 Jul;12(7):439-445 [FREE Full text] [Medline: 9229283]

16. Arroll B, Goodyear-Smith F, Kerse N, Fishman T, Gunn J. Effect of the addition of a "help" question to two screening questions on specificity for diagnosis of depression in general practice: diagnostic validity study. BMJ 2005 Oct 15;331(7521):884 [FREE Full text] [doi: 10.1136/bmj.38607.464537.7C] [Medline: 16166106]

17. Austin MP, Colton J, Priest S, Reilly N, Hadzi-Pavlovic D. The Antenatal Risk Questionnaire (ANRQ): acceptability and use for psychosocial risk assessment in the maternity setting. Women Birth 2013 Mar;26(1):17-25. [doi: 10.1016/j.wombi.2011.06.002] [Medline: 21764399]

18. Bosanquet K, Bailey D, Gilbody S, Harden M, Manea L, Nutbrown S, et al. Diagnostic accuracy of the Whooley questions for the identification of depression: a diagnostic meta-analysis. BMJ Open 2015 Dec 09;5(12):e008913 [FREE Full text] [doi: 10.1136/bmjopen-2015-008913] [Medline: 26656018]

19. Christl B, Reilly N, Smith M, Sims D, Chavasse F, Austin MP. The mental health of mothers of unsettled infants: is there value in routine psychosocial assessment in this context? Arch Womens Ment Health 2013 Oct;16(5):391-399. [doi: 10.1007/s00737-013-0360-0] [Medline: 23775393]

20. Christl B, Reilly N, Yin C, Austin MP. Clinical profile and outcomes of women admitted to a psychiatric mother-baby unit. Arch Womens Ment Health 2015 Dec;18(6):805-816. [doi: 10.1007/s00737-014-0492-x] [Medline: 25591925] 
21. Begley C, Shegog R, Harding A, Goldsmith C, Hope O, Newmark M. Longitudinal feasibility of MINDSET: a clinic decision aid for epilepsy self-management. Epilepsy Behav 2015 Mar;44:143-150. [doi: 10.1016/j.yebeh.2014.12.031] [Medline: 25705825]

22. Reilly N, Harris S, Loxton D, Chojenta C, Forder P, Austin MP. The impact of routine assessment of past or current mental health on help-seeking in the perinatal period. Women Birth 2014 Dec;27(4):e20-e27. [doi: 10.1016/j.wombi.2014.07.003] [Medline: 25154772]

23. Reilly N, Yin C, Monterosso L, Bradshaw S, Neale K, Harrison B, et al. Identifying psychosocial risk among mothers in an Australian private maternity setting: A pilot study. Aust N Z J Obstet Gynaecol 2015 Oct;55(5):453-458. [doi: 10.1111/ajo.12370] [Medline: 26222838]

24. Kalra H, Reilly N, Austin MP. An evaluation of routine antenatal depression screening and psychosocial assessment in a regional private maternity setting in Australia. Aust N Z J Obstet Gynaecol 2018 Dec;58(6):629-635. [doi: 10.1111/ajo.12777] [Medline: 29380345]

25. Priest SR, Austin MP, Barnett BB, Buist A. A psychosocial risk assessment model (PRAM) for use with pregnant and postpartum women in primary care settings. Arch Womens Ment Health 2008 Dec;11(5-6):307-317. [doi: 10.1007/s00737-008-0028-3] [Medline: 18726142 ]

26. Howard LM, Ryan EG, Trevillion K, Anderson F, Bick D, Bye A, et al. Accuracy of the Whooley questions and the Edinburgh Postnatal Depression Scale in identifying depression and other mental disorders in early pregnancy. Br J Psychiatry 2018 Jan;212(1):50-56 [FREE Full text] [doi: 10.1192/bjp.2017.9] [Medline: 29433610]

27. van Heyningen T, Honikman S, Tomlinson M, Field S, Myer L. Comparison of mental health screening tools for detecting antenatal depression and anxiety disorders in South African women. PLoS One 2018;13(4):e0193697 [FREE Full text] [doi: 10.1371/journal.pone.0193697] [Medline: 29668725]

28. Drake E, Howard E, Kinsey E. Online screening and referral for postpartum depression: an exploratory study. Community Ment Health J 2014 Apr;50(3):305-311 [FREE Full text] [doi: 10.1007/s10597-012-9573-3] [Medline: 23283485]

29. Kingston DE, Biringer A, Toosi A, Heaman MI, Lasiuk GC, McDonald SW, et al. Disclosure during prenatal mental health screening. J Affect Disord 2015 Nov 1;186:90-94. [doi: 10.1016/j.jad.2015.07.003] [Medline: 26233318]

30. Buist A, O'Mahen H, Rooney R. Acceptability, attitudes and overcoming stigma. In: Gemmill A, Milgrom J, editors. Identifying Perinatal Depression and Anxiety: Evidence-Based Practice in Screening, Psychosocial Assessment and Management. Chichester, West Sussex: John Wiley \& Sons, Ltd; 2015:51-62.

31. Forder PM, Rich J, Harris S, Chojenta C, Reilly N, Austin MP, et al. Honesty and comfort levels in mothers when screened for perinatal depression and anxiety. Women Birth 2020 Mar;33(2):e142-e150. [doi: 10.1016/j.wombi.2019.04.001] [Medline: 31133524]

32. Dennis C, Chung-Lee L. Postpartum depression help-seeking barriers and maternal treatment preferences: a qualitative systematic review. Birth 2006 Dec;33(4):323-331. [doi: 10.1111/j.1523-536X.2006.00130.x] [Medline: 17150072]

33. Smith T, Gemmill AW, Milgrom J. Perinatal anxiety and depression: Awareness and attitudes in Australia. Int J Soc Psychiatry 2019 Aug;65(5):378-387. [doi: 10.1177/0020764019852656] [Medline: 31148499]

34. Woolhouse H, Brown S, Krastev A, Perlen S, Gunn J. Seeking help for anxiety and depression after childbirth: results of the Maternal Health Study. Arch Womens Ment Health 2009 Apr;12(2):75-83. [doi: 10.1007/s00737-009-0049-6] [Medline: 19214705]

35. Reay R, Matthey S, Ellwood D, Scott M. Long-term outcomes of participants in a perinatal depression early detection program. J Affect Disord 2011 Mar;129(1-3):94-103. [doi: 10.1016/j.jad.2010.07.035] [Medline: 20800898]

36. Rowe HJ, Holton S, Fisher J. Postpartum emotional support: a qualitative study of women's and men's anticipated needs and preferred sources. Aust J Prim Health 2013;19(1):46-52. [doi: 10.1071/PY11117] [Medline: 22951012]

37. PDeC. MumSpace: Support for the emotional health of new mums, at every step.: Perinatal Depression e-Consortium (PDeC); 2018. URL: https://www.mumspace.com.au/ [accessed 2020-10-15]

38. Parker G, Blanch B, Fletcher K, Greenfield L. Evaluating the utility of a bipolar self-test screening measure. Australas Psychiatry 2011 Aug;19(4):317-320. [doi: 10.3109/10398562.2011.578642] [Medline: 21879866]

39. Parker G, Fletcher K. The 'real world' utility of a web-based bipolar disorder screening measure: a replication study. J Affect Disord 2013 Sep 05;150(2):276-283. [doi: 10.1016/j.jad.2013.04.006] [Medline: 23701751]

40. Parker G, Fletcher K, Blanch B, Greenfield L. Take-up and profile of individuals accessing a web-based bipolar self-test screening measure. J Affect Disord 2012 Apr;138(1-2):117-122. [doi: 10.1016/j.jad.2011.12.013] [Medline: 22284017]

41. Parker G, Fletcher K, Blanch B, Greenfield L. The 'real world' utility of a web-based bipolar disorder screening measure. Acta Psychiatr Scand 2013 May;127(5):373-380. [doi: 10.1111/acps.12017] [Medline: 23039131]

42. Kingston D, Biringer A, Veldhuyzen van Zanten S, Giallo R, McDonald S, MacQueen G, et al. Pregnant Women's Perceptions of the Risks and Benefits of Disclosure During Web-Based Mental Health E-Screening Versus Paper-Based Screening: Randomized Controlled Trial. JMIR Ment Health 2017 Oct 20;4(4):e42 [FREE Full text] [doi: 10.2196/mental.6888] [Medline: 29054833] 


\section{Abbreviations}

ANRQ: Antenatal Risk Questionnaire

HREC: Human Research Ethics Committee

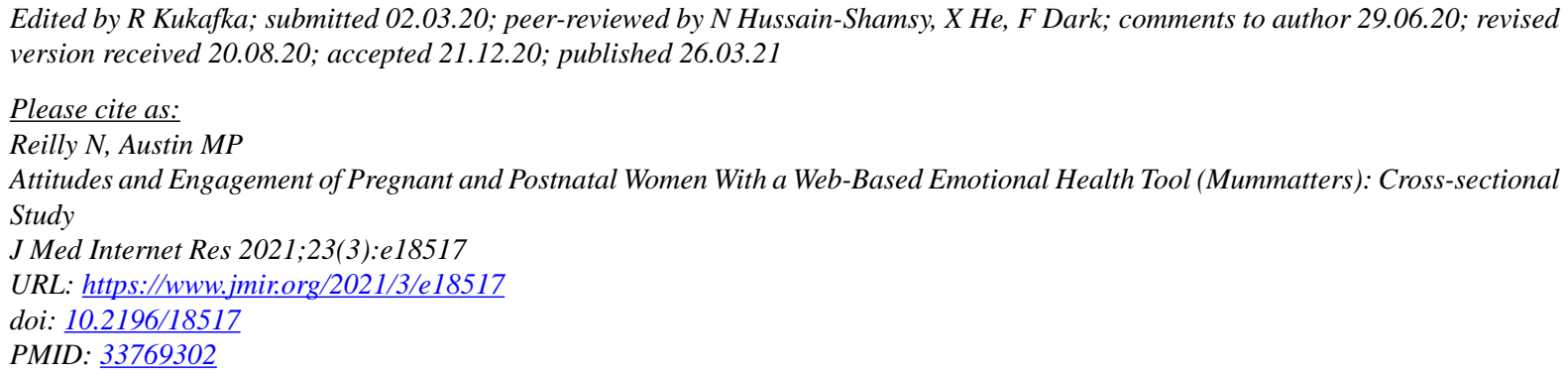

(CNicole Reilly, Marie-Paule Austin. Originally published in the Journal of Medical Internet Research (http://www.jmir.org), 26.03.2021. This is an open-access article distributed under the terms of the Creative Commons Attribution License (https://creativecommons.org/licenses/by/4.0/), which permits unrestricted use, distribution, and reproduction in any medium, provided the original work, first published in the Journal of Medical Internet Research, is properly cited. The complete bibliographic information, a link to the original publication on http://www.jmir.org/, as well as this copyright and license information must be included. 